\title{
Intrapulmonary Bronchogenic Cyst
}

\author{
Ahmad K, Rauniyar RK, Gupta MK \\ Department of Radiodiagnosis and Imaging, BPKIHS, Dharan, Nepal
}

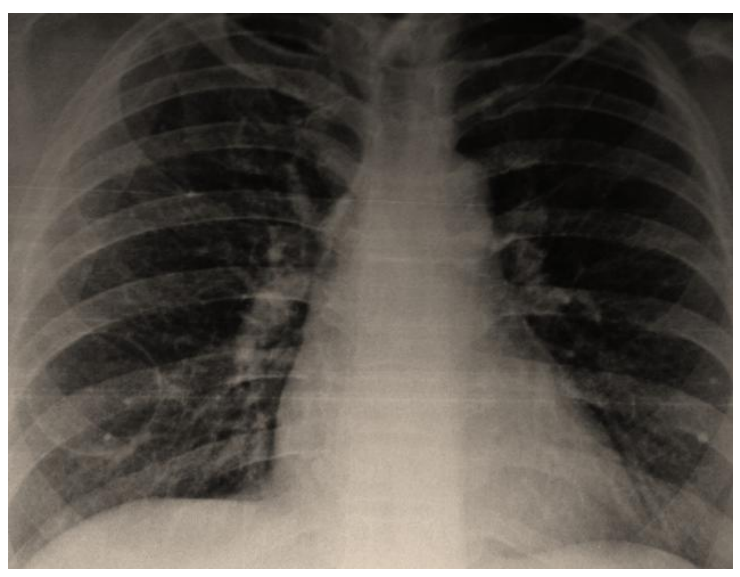

Fig. 1: Chest X-ray PA view showing a well defined cystic lesion in right lower zone.

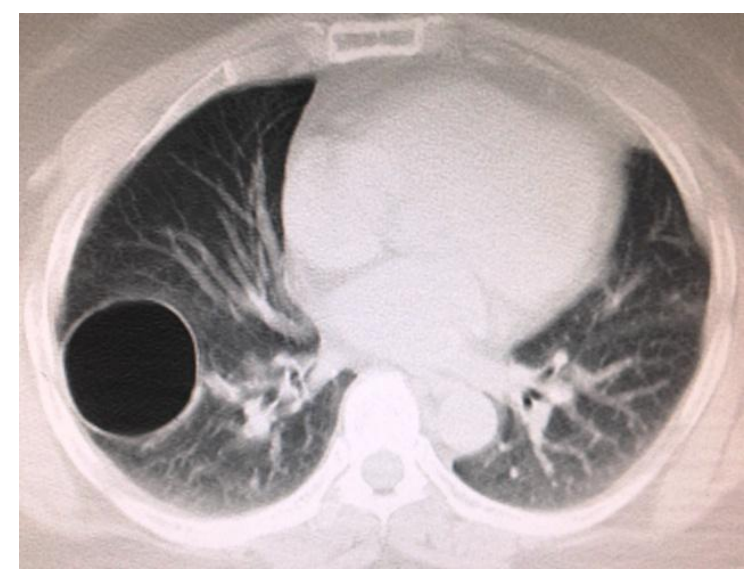

Fig. 2: CT Chest (Lung window) showing a well defined air containing cystic lesion in right lower lobe.

Bronchogenic cysts are congenital lesions arising from the abnormal budding of the ventral foregut that occurs between $26^{\text {th }}$ and $40^{\text {th }}$ days of gestation and accounts for $10 \%-29 \%$ of all congenital cysts. Most of the cysts are located in the mediastinum along the tracheobronchial tree, but they can also be found in the lung parenchyma or may extend to or below the diaphragm as dumb-bell cysts and is usually located in the lower lobes. ${ }^{1,2}$ The patient 26 years old male presented with productive cough for the last 2 months which was not associated with fever, loss of weight or appetite. Plain radiograph of the chest PA view shows (Fig.1) cystic lesion in the right lower zone. Computed tomographic scan shows (Fig.2) a well defined thin walled intrapulmonary air containing cystic lesion in the right lower lobe. It is advocated by many authors that bronchogenic cyst should be resected surgically.,

\section{References}

1. McAdams HP, Kirejczyk WM, Rosado-de-Christenson ML, Matsumoto S. Bronchogenic cyst: Imaging features with clinical and histopathological correlation. Radiology 2000;217:441-446.

2. Nuchtern JG, Harberg FJ. Congenital lung cysts. Semin Pediatr Surg 1994;3:223-243.

3. Aktogu S, Yuncu G, Halil Colar H, Ermete S, Buduneli T. Bronchogenic cysts: clinicopathological presentation and treatment. Eur Respir J 1996;9:2017-2021.

4. Patel S, Meeker D, Biscotti C, Kirby T, Rice T. Presentation and management of bronchogenic cysts in the adults. Chest 1994;106:79-85. 